\title{
Releasing Time to Care
}

Jane Coutts

Saskatchewan's Health Quality Council (HQC) was launched in 2003 with a mandate to not only measure and report on healthcare but also work with a range of partners to improve the province's health system. In late 2007, HQC's board decided it was time for Saskatchewan to reinvent its healthcare system, using the highestperforming systems in the world as its model. And in 2008, HQC launched Accelerating Excellence, a multi-level program to rethink, redesign and renew healthcare.

To help maintain momentum and show other provinces whether high-performing healthcare can be achieved in Canada, HQC is documenting its journey toward high-performing healthcare. This second article in this series discusses the Releasing Time to Care ${ }^{\mathrm{TM}}$ program.

I n Prince Albert's Victoria Hospital, nurses on the surgery ward don't have much doubt that the Releasing Time to Care ${ }^{\mathrm{TM}}$ (RTC) program has opened a doorway to a better world - although, technically speaking, the doorway in question is between the medication and intravenous equipment storage rooms. That doorway, cut through a wall that has separated the two rooms for decades, eliminates the 20 steps it took to go out one door and in another, steps that had to be taken each and every time a nurse was gathering both medications and intravenous (IV) supplies for a patient. Steps taken dozens of times a day, hundreds of times a year. Sheila Cooper, nursing unit manager on the ward, estimates the doorway will save 210 nursing hours a year. In the language of Britain's National Health Service Institute for Innovation and Improvement (which developed the program), this is time that's now released for care.

The doorway is only a minuscule part of the transformation Releasing Time to Care ${ }^{\mathrm{TM}}$ is intended to bring about in healthcare in Saskatchewan. But it's an important one. It's tangible and practical, and - according to one doctor on the ward - the doorway alone has improved morale on the nursing team. All of this should add up to better care for patients.

That, at least, is what HQC believed when it made Releasing Time to Care ${ }^{\mathrm{TM}}$ part of its Accelerating Excellence program. Based on Lean methods developed by Toyota to improve indus- trial productivity, RTC is designed to deliver better nursing to acute care wards. Saskatchewan is one of the first places outside of Britain to try the program.

Nurse Denise Ksyniuk is the leader of the team that cleaned out and reorganized the storage rooms using Lean methods for making workplaces more efficient. She's almost dancing as she shows it off to a group of visitors: "It's so exciting. I'm so excited!" she says, confessing she has trouble making herself go through all the proper steps in the RTC procedure now that she's begun - she just wants to keep cleaning. But the essence of the program is teamwork: front-line workers gathering and analyzing evidence, and then working together, step-by-step with the RTC tool kit, to improve their environment and their activities.

Kyla Avis, a registered nurse and HQC's program director for Releasing Time to Care ${ }^{\mathrm{TM}}$, states that the program is a "micro version" of Quality as a Business Strategy, the section of Accelerating Excellence that gives healthcare leaders the knowledge and skills they need to create system-level change. Like Quality as a Business Strategy, RTC helps participants see the system - in this case, the ward and the care that takes place on it - as a whole and to focus on improving care for the patient.

\section{The essence of the program is} teamwork: front-line workers gathering and analyzing evidence, and working together to improve their environment and their activities.

Saskatchewan's RTC program began with a trip to England in September 2008 by a group of HQC staff, leaders from the nursing unions and regulatory bodies, health region staff and the deputy minister and minister of health. Seven people, including Avis, learned how to be trainers in the program. Testing the concept for Saskatchewan began in the medicine unit at Moose Jaw's Union Hospital in November, 2008 and in the oncology ward at Regina's Pasqua Hospital in January 2009. A report on 
those early days, released in September 2009, is available on the HQC website (Avis 2009; available at http://www.hqc.sk.ca). It gives more details than there is room for here.

Briefly, however, Releasing Time to Care ${ }^{\mathrm{TM}}$ is based on growing evidence that involving front-line workers in quality improvement is essential for large, sustainable transformations in healthcare. The program comes as a boxed set of 11 modules, plus guides for leaders and the tool kit itself, with step-by-step outlines for planning and executing change. Ward teams gather data on everything from patient falls and infections to staff sick days. They mix it with staff and patient surveys, photos of the state of the ward and recording of what nurses are doing at various points throughout a shift. Then, using the tool kit, and with training and advice from HQC, they begin the transformation.

Wards are given three to four months to do groundwork mainly intense communicating of what RTC is about. Because hospitals are systems, a ward can't change how it works without changes throughout the system. "Pre-implementation time" is needed to create and entrench support from all, including administrators, executives and the board, from everyone on the ward and from all the departments that support it, such as laundry, maintenance, housekeeping, pharmacy and nutrition.

A heavy-duty information campaign is also needed to counter rumours. Nurses often fear RTC, suspecting that it's a prelude to job cuts or will increase their workloads. Other employees on the ward and in other departments may think that it's just a way for nurses to offload work. Both a union official and a manager said in interviews that they had worried that the "released" time would be wasted in chatting and coffee breaks.

Those doubts have to be dealt with, notes Carolyn Bremner, ward lead on Releasing Time to Care ${ }^{\mathrm{TM}}$ in Moose Jaw's medical unit. She explains that they didn't communicate nearly enough, thinking a few presentations ensured that staff understood the overall goals and possibilities of RTC. But they soon realized that staff thought it was simply a Lean-style tidy up. "We had to go back and show them the videos, and do more newsletters, and a lot of one-on-one. You have to take the pre-implementation time and really make sure management, the board, doctors and everyone know what you're doing and why."

Bremner feels the problem was partly because they chose not to start with Knowing How We're Doing (KHWD, in the program's acronym-loaded language), instead beginning with the Well-Organized Ward. Knowing How We're Doing is all about measuring - whether it's falls, infections, staff sick days or patient satisfaction, the evidence gathered is the foundation of all the work that follows. The results are posted on the KHWD board and discussed in weekly meetings. From that, the targets for improvement are chosen.

That's usually when Well-Organized Ward begins: with a vision statement prepared and agreed to by all the staff, and a baseline of knowledge about the work the ward does, staff can look at the space and what's done in it. They take photos, videotape "waste walks" and trace on floor plans the standard routes nurses follow as they work. They do "activity follows" recording what a selected nurse is doing in every minute of a shift. Combined, these measures show wasted space, motion and time - the information needed to transform a typical ward to a well-organized one.

The final foundation module, Patient Status at a Glance (PSAG), centralizes patient information in a single spot (usually a white board, but in some cases, a computer screen). The intent is to keep all staff equally informed. Shift handovers and patient conferences are done in front of the PSAG board. Therefore, it's much less likely that an important detail will be noted only on a scrap of paper somewhere.

Releasing Time to Care ${ }^{\mathrm{TM}}$ follows the plan-do-study-act cycle of continuous improvement. Posting information is integral to the process - staff gather at the KHWD board once a week, and the status-at-a-glance board every shift change. Sticky notes let workers join ongoing discussions even when they're not on shift. Changes are followed up with detailed formal audits to measure results. When it seems clear a new approach is both successful and well established, audits are done less often.

When the three foundation modules are completed, wards can choose what to focus on next from the eight process modules: medicines, shift handover, patient observations, admission and discharge, meals, nursing procedures, ward rounds and patient hygiene.

\section{"Start really small and build, because one project always leads to another."}

Bremner warns people starting the program to be cautious. "Start really small and build, because one project always leads to another," she explains. "We were far too enthusiastic without realizing how much work this was going to be." Generally, it's easy to get people involved in WOW because purging closets or setting up better IV trays gives immediate returns. KHWD, on the other hand, adds a lot of work, without quick returns. And PSAG boards are hard for wards to master: people usually start by posting far too much detail, which makes using a white board cumbersome. There are also concerns about confidentiality.

Kim Parish is an Releasing Time to Care ${ }^{\mathrm{TM}}$ trainer from England; she went to Saskatchewan to do site visits and training in November of 2009. She explains that the demands of RTC can make it hard to keep going, until it starts to spread and sustain itself because people have noticed it makes life easier. The problem is that, at first, any time freed is almost inevitably sucked up by the demands of the next innovation. Avis says that's 
why the HQC is emphasizing "rebalancing" over "releasing" time. Efficiency is not everything - a faster medication round isn't an improvement if important teaching about the medications is missed.

Despite RTC's emphasis on grassroots change, it is always made clear the program cannot work without strong leadership - and getting real leadership, not just lip-service support, has been a problem in Saskatchewan. As part of the program, leaders are supposed to make regular visits to wards. Avis states that most of them do, but they're often rushed, and leaders don't take time to talk with patients and staff. The lack of leadership support shows in other ways too. HQC has given grants to health regions to offset the cost of testing RTC. For some wards, getting the money - to purchase a printer or laminator, for example - can take many frustrating weeks. Wards with leaders who are committed to the program tend to get what they need right away.

Bonnie Brossart, chief executive officer of HQC, recently wrote a letter to CEOs reminding them that they have an important role to play in the success of the program. "Releasing Time to Care is about giving nurses tools to do their jobs differently, but it's also about helping leaders learn how to lead in new ways," explains Brossart. "Teams want the opportunity to have open and honest discussion with their executive leaders, and executive leaders must honour that."

It is early days to judge the impact of RTC. Avis, who has been advising an Ontario group trying to introduce RCT, warned them their 12-month trial period was unlikely to produce any meaningful improvements in safety or efficiency. But she did have some positive numbers in her September 2009 report. The oncology ward at Pasqua Hospital in Regina upped the early identification of possible Clostridium difficile infections from 14 to $63 \%$ on night shifts and from 70 to $77 \%$ on days. The same group calculated that their Well-Organized Ward work released 13 minutes a shift, or 13 nursing shifts a year. In Moose Jaw, Bremner calculates that their Patient Status at a Glance efforts have freed up the equivalent of one full-time nurse a year for more hands-on patient care. Those kind of statistics, however, may prompt fears of layoffs rather than a vision of more time for patients; Avis has learned to avoid talking about released time in those terms. Many wards report better staff and patient satisfaction.

Eighteen months into the program, Avis was so inundated with calls for information, she had to ask people in other provinces to coordinate their questions so she could handle them all: RTC is stirring up interest all over the country and the world. She's glad of that, and of the response in Saskatchewan, but she urges caution all the same.

"It's a ton of work. It's change management to the 100th degree," she told a meeting of the Saskatchewan Union of Nurses in November. "We're saying, 'Yes, it's difficult, but it's difficulty

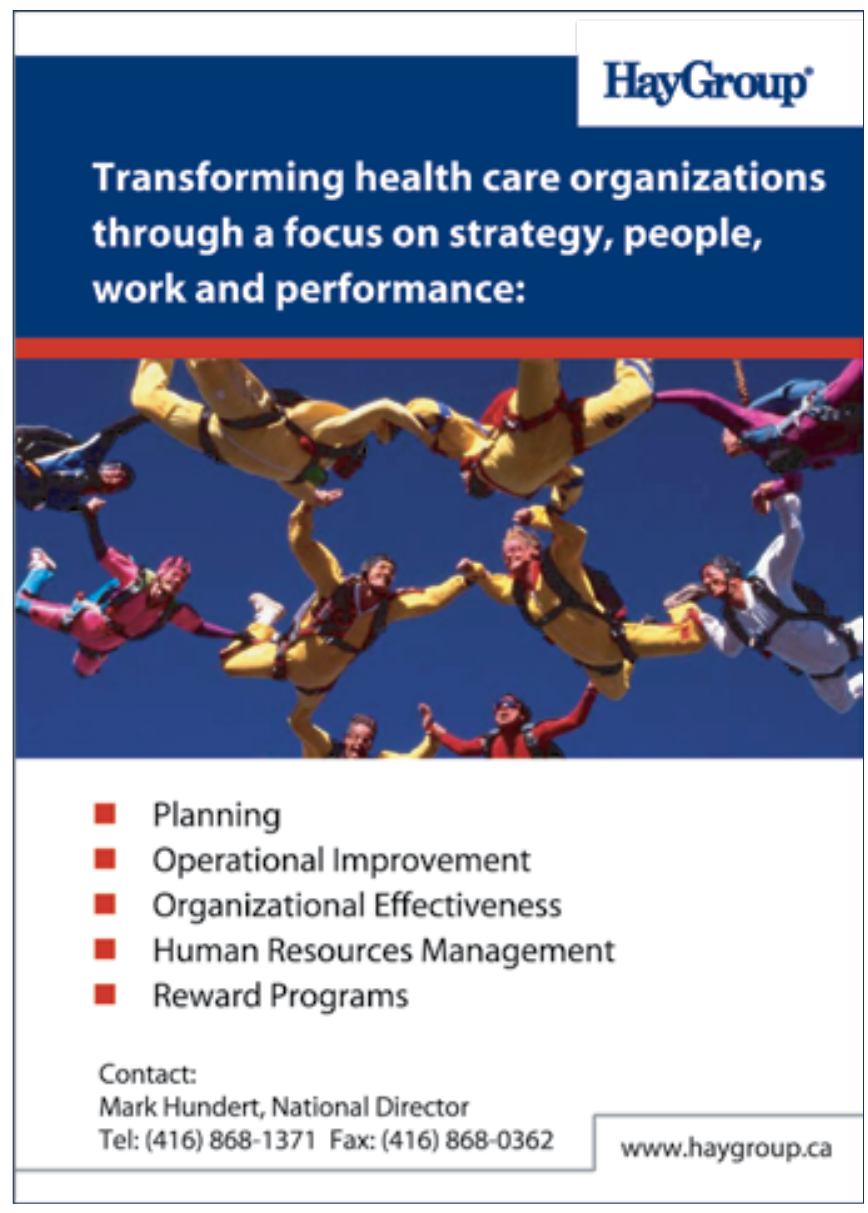

that is worthwhile.' It's long-term change; it's something you will do forever. We are quite positive that it's not just another flavour of the month. We are positive we can sustain it." HQ

\section{Reference}

Avis, K. 2009. Releasing Time to Care in Saskatchewan: Promising Signs that Program Engages Clinicians. Saskatoon, SK: Health Quality Council.

\section{About the Author \\ Jane Coutts is a healthcare writer based in Ottawa, Ontario. This article was commissioned by the Health Quality Council.}

